\title{
Mechanisms of Eosinophil Adherence to Cultured Vascular Endothelial Cells Eosinophils Bind to the Cytokine-induced Endothelial Ligand Vascular Cell Adhesion Molecule-1 via the Very Late Activation Antigen-4 Integrin Receptor
}

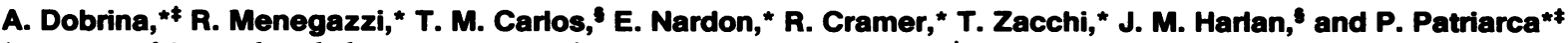 \\ ${ }^{*}$ Institute of General Pathology, University of Trieste, Trieste, Italy 34127; ${ }^{\ddagger}$ Carlo and Dirce Callerio Foundation, Trieste, Italy $34127 ;$ \\ and ${ }^{8}$ Department of Medicine, University of Washington, Seattle, Washington 98195
}

\begin{abstract}
We have examined the mechanisms involved in the adherence of normal peripheral blood eosinophils to cultured human umbilical vein endothelial cells (HEC) under three conditions: (a) adherence in the absence of treatment of HEC or eosinophils with activating agents (basal adherence); (b) adherence induced by stimulation of eosinophils with phorbol ester (eosinophil-dependent adherence); and (c) adherence induced by pretreatment of HEC with LPS, tumor necrosis factor (TNF), or IL-1 (endothelial-dependent adherence). A mechanism was identified that was equally active in basal, eosinophil-dependent, and endothelial-dependent adherence. This mechanism was optimally active in the presence of both $\mathrm{Ca}^{++}$and $\mathrm{Mg}^{++}$, and reduced in the presence of $\mathrm{Ca}^{++}$only or $\mathrm{Mg}^{++}$only. Furthermore, like the other mechanisms of eosinophil adherence, it was active at $37^{\circ} \mathrm{C}$ but not at $4^{\circ} \mathrm{C}$. A second mechanism of adherence was involved in eosinophil- and in endothelial-dependent adherence. This mechanism was dependent on the CD11/CD18 adhesion complex of eosinophils (i.e., inhibited by anti-CD18 $\mathrm{MAb}$ ) and it was active in the presence of $\mathrm{Ca}^{++}$and $\mathrm{Mg}^{++}$or $\mathrm{Mg}^{++}$only, but not $\mathrm{Ca}^{++}$only. The third mechanism of adherence was specific for endothelial-dependent adherence. It involved the endothelial ligand vascular cell adhesion molecule-1 (VCAM-1) and the eosinophil receptor very late activation antigen-4 (VLA-4, CD49d/CD29, i.e., inhibited by anti-VCAM-1 MAb or anti-VLA-4 MAb). This mechanism was active in the presence of $\mathrm{Ca}^{++}$and $\mathrm{Mg}^{++}$but not of $\mathrm{Ca}^{++}$only or $\mathrm{Mg}^{++}$only, and was not up- or downregulated when eosinophils were stimulated with phorbol ester. In contrast, the endothelial leukocyte adhesion molecule-1 (ELAM-1), that binds neutrophils and monocytes, was not involved in eosinophil adherence to LPS-, TNF-, or IL-1-stimulated HEC (i.e., not inhibited by antiELAM-1 MAb). We conclude that eosinophils, like monocytes and lymphocytes, bind to the cytokine-induced endothelial ligand VCAM-1 via the integrin receptor VLA-4. (J. Clin. Invest. 1991. 88:20-26.) Key words: vascular cell adhesion molecule-1 • very late activation antigen- $4 \cdot$ eosinophil $•$ endothelium - adherence
\end{abstract}

Address correspondence to Dr. John M. Harlan, Division of Hematology, Room 10, University of Washington, Seattle, WA 98195.

Received for publication 9 May 1990 and in revised form 17 December 1990.

J. Clin. Invest.

(c) The American Society for Clinical Investigation, Inc. 0021-9738/91/07/0020/07 \$2.00

Volume 88, July 1991, 20-26

\section{Introduction}

Mature eosinophils are located predominantly in the extravascular space, even in physiologic conditions $(1-3)$, the skin, gastrointestinal tract, and mucosa of the bronchi being the most heavily infiltrated tissues $(3,4)$. Increased levels of circulating eosinophils and local accumulation of eosinophils at sites of acute or chronic inflammation have long been associated with allergic reactions, parasitic infestations, and other acute and chronic inflammatory diseases such as thyroiditis, some stages of tuberculosis, mycotic infections, recurrent staphylococcal infection, Hodgkin's disease, and other neoplastic processes (recently reviewed by Nutman et al. [5, 6] and by Spry [7]). A series of studies has emphasized the role played in eosinophilmediated inflammatory reactions by powerful toxic mechanisms of eosinophils, such as the eosinophilic peroxidase-hydrogen peroxide-halide system (8-10) and the release of eosinophil major basic protein $(11,12)$. In contrast, little is known about the mechanisms involved in the localization of eosinophils in tissues, both in physiologic and pathologic conditions. Eosinophil adherence to endothelial cells, a key event in leukocyte emigration into tissues (13), was recently examined by Lamas et al. (14) and by Kimani et al. (15). The authors have documented at least three mechanisms of eosinophil adherence to cultured human umbilical vein endothelial cells $\left(\right.$ HEC) ${ }^{1}:(a)$ adherence of unstimulated eosinophils to resting HEC (basal adherence); (b) adherence of eosinophils stimulated by chemotactic factors, such as platelet activating factor (PAF) $(16,17)$, or by phorbol ester (PMA) to resting HEC (eosinophil-dependent adherence); and (c) adherence of resting eosinophils to HEC stimulated by cytokines, such as tumor necrosis factor (TNF) and IL-1, or LPS (endothelial-dependent adherence). The eosinophil-dependent adherence mechanism, similar to that of stimulated neutrophils $(18,19)$, involves activation of the leukocyte adhesion complex CD11/CD18, as judged by inhibition by $\operatorname{CD} 18 \operatorname{MAb}(14,15)$. Furthermore, as already reported for neutrophils $(18,19)$, the endothelial-dependent adherence of eosinophils is only partially inhibited by CD18 MAb, suggesting involvement of a second, CD18-independent adherence mechanism (15). Finally, basal adherence of eosinophils is independent of CD11/CD18 complex, since it is not affected by CD11/CD18 MAb (14).

In this paper we present evidence that several features of

1. Abbreviations used in this paper: ELAM-1, endothelial leukocyte adhesion molecule-1; HEC, human umbilical vein endothelial cells; ICAM-1, intercellular adhesion molecule-1; LAD, leukocyte adhesion deficiency; PAF, platelet activating factor (1-alkyl-2-acetyl-sn-glycero3-phosphorylcholine); TNF, tumor necrosis factor; VCAM-1, vascular cell adhesion molecule-1; VLA-4, very late activation antigen-4. 
eosinophil adherence are clearly distinct from those of neutrophils, most notably: $(a)$ basal adherence of eosinophils is higher than that of neutrophils, is temperature-dependent, and requires $\mathrm{Ca}^{++}$and $\mathrm{Mg}^{++}$; (b) the CD11/CD18-independent component of eosinophil adherence to LPS-, TNF-, or IL-1treated HEC involves the very late activation antigen-4 (VLA4) (CD49d/CD29) integrin receptor (20) on the eosinophil and vascular cell adhesion molecule-1 (VCAM-1 [21]; inducible cell adhesion molecule-110 (INCAM)-110 [22]), an endothelial cell molecule that promotes adherence of peripheral blood lymphocytes $(22,23)$ and monocytes $(22,24)$, but not neutrophils; and $(c)$ the CD11/CD18-independent eosinophil adherence to cytokine- or LPS-stimulated HEC is not downregulated after direct activation of eosinophils, as occurs with neutrophils (25).

\section{Methods}

Cell culture. HEC were prepared by collagenase treatment of the vessels as described elsewhere (26) and maintained in endotoxin-free RPMI 1640 medium (Gibco-BRL, Uxbridge, UK) supplemented with $10 \%$ newborn bovine serum (Flow Laboratories Ltd., Irvine, Scotland, UK) and $10 \%$ fetal calf serum (Biochrom KG, Berlin, FRG) (NBSFCS). Passaged HEC were maintained in RPMI 1640 supplemented with $20 \%$ NBS-FCS containing heparin $(90 \mu \mathrm{g} / \mathrm{ml}$; Sigma Chemical Co., St. Louis, MO) and endothelial cell growth factor $(50 \mu \mathrm{g} / \mathrm{ml})$ as described by Thornton et al. (27). Endothelial cell growth factor was prepared from bovine hypothalamus according to the method of Maciag et al. (28).

Neutrophil isolation. Peripheral blood was obtained by venipuncture from healthy donors. The blood was collected in syringes containing 15\% (vol:vol) sterile ACD solution (acid-citrate-dextrose; $100 \mathrm{mM}$ disodium citrate, $128 \mathrm{mM}$ glucose; $\mathrm{pH} 5.0$ ), and the neutrophils were isolated by Ficoll-Hypaque (Pharmacia Fine Chemicals, Uppsala, Sweden) gradient centrifugation, 3\% dextran sedimentation, and hypotonic saline lysis of contaminating red cells (29). This procedure resulted in a preparation $>95 \%$ neutrophils, which exceeded $95 \%$ viability by trypan blue dye exclusion. Isolated peripheral blood neutrophils were washed with PBS (Gibco-BRL) and suspended at a final concentration of $7 \times 10^{5}$ cells/ml in PBS containing $5 \mathrm{mM}$ glucose, $1 \mathrm{mM}$ $\mathrm{CaCl}_{2}$, and $1 \mathrm{mM} \mathrm{MgCl}$, unless otherwise stated.

Eosinophil isolation. Eosinophils were isolated according to the method of R. Cramer (manuscript in preparation). Peripheral blood from healthy donors containing $<2 \times 10^{5}$ eosinophils $/ \mathrm{ml}$ was collected in ACD solution. After erythrocyte sedimentation in $4.5 \%$ dextran (Pharmacia), the white cell-rich plasma was washed once with PBS containing $13 \mathrm{mM}$ sodium citrate and $0.5 \%$ BSA (Miles Laboratories Inc., Goodwood, South Africa). The cell pellet was then resuspended in isotonic Percoll (Pharmacia) containing $13 \mathrm{mM}$ sodium citrate and $0.5 \%$ BSA ( $\mathrm{pH} 7.4$ ). The density of the Percoll suspension was $1.0853 \pm 0.0002 \mathrm{~g} / \mathrm{ml}$, as measured at $20^{\circ} \mathrm{C}$ by a DMA 45 density meter (A. Paar, Graz, Austria), and Percoll osmotic value was $290 \pm 2$ mosM, as measured by cryoscopic osmometer (Osmomat 030; Gonotec, Berlin, FRG). The cell suspension was layered on a Percoll cushion with a density higher than $1.1 \mathrm{~g} / \mathrm{ml}$ and was centrifuged at $1,000 \mathrm{~g}$ for $20 \mathrm{~min}$ at $20^{\circ} \mathrm{C}$. The cell ring formed at the interface was collected and the red cells present were removed by hypotonic lysis at $4^{\circ} \mathrm{C}$. Isolated peripheral blood eosinophils were washed with PBS and suspended at a final concentration of $3 \times 10^{5}$ cells $/ \mathrm{ml}$ in PBS containing $5 \mathrm{mM}$ glucose, 1 $\mathrm{mM} \mathrm{CaCl}$, and $1 \mathrm{mM} \mathrm{MgCl}$, unless otherwise stated. The resulting cell suspension contained between $85 \%$ and $98 \%$ eosinophils and the yield was $>50 \%$ of the eosinophils present in the starting blood sample. Cell viability was $>98 \%$, as determined by the trypan blue dye exclusion test.

Adherence assay. First to third passage HEC were harvested with 0.05 trypsin and $0.02 \%$ EDTA in balanced salt solution (Gibco-BRL).
The cells were then plated in 6.4-mm diameter wells (Costar Cluster, Cambridge, MA) at $1.5 \times 10^{4}$ cells/ml in RPMI 1640 supplemented with $20 \%$ NBS-FCS. Visually confluent monolayers were formed after overnight incubation. Cells were pretreated with reagents for $4 \mathrm{~h}$, and the monolayers were then washed with a three-well volume of PBS. For the adherence assay at $4^{\circ} \mathrm{C}$, after the incubation at $37^{\circ} \mathrm{C}, \mathrm{HEC}$ were incubated for $30 \mathrm{~min}$ in a cold room $\left(2-4^{\circ} \mathrm{C}\right)$ and washed with a threewell volume exchange of ice-cold PBS. Eosinophils or neutrophils were then added $\left(70 \mu \mathrm{l} /\right.$ well). Leukocytes for the $4^{\circ} \mathrm{C}$ adherence assay were incubated for $30 \mathrm{~min}$ on ice before addition to the wells. Leukocytes and HEC were then incubated for $30 \mathrm{~min}$ at $37^{\circ} \mathrm{C}$ or in the cold room. After incubation the monolayers were washed with a two-well volume exchange of PBS or ice-cold PBS to remove nonadherent leukocytes. A colorimetric assay was then applied to detect the eosinophils or neutrophils adhering to the monolayers, using tetramethylbenzidine (TMB) as peroxidase substrate (30). The substrate solution consisted of $2 \mathrm{mM}$ TMB (Sigma) in $0.1 \mathrm{M}$ sodium acetate buffer, ( $\mathrm{pH} 4.2$ ) containing $0.1 \%$ (wt:vol) cetitrimethylammonium bromide (Sigma) as peroxidase solubilizing agent. In this assay eosinophils show a $>10$ times higher peroxidase activity than neutrophils on a per cell basis, thus ruling out any significant interference by the few contaminating neutrophils. When neutrophil adherence was assayed, the selective eosinophil peroxidase inhibitor 3 amino-1,2,4 triazol (1 mM; Schuchardt, Munich, FRG) (31) was also added to the substrate solution to abolish the interference by eosinophils. The substrate solution was then added to the monolayers ( $75 \mu \mathrm{l} /$ well) followed, after $2 \mathrm{~min}$, by $0.7 \mathrm{mM}$ hydrogen peroxide $(75 \mu \mathrm{l} /$ well). After $2 \mathrm{~min}$ of incubation at room temperature, the peroxidase reaction was stopped by the addition of $50 \mu l$ of $4 \mathrm{~N}$ acetic acid, containing $10 \mathrm{mM}$ sodium azide. The absorbance was then determined at $620 \mathrm{~nm}$ using a Titertek Multiskan (Flow Laboratories, Inc., McLean, VA). Percent leukocyte adherence was calculated using a calibration curve. This was obtained by performing the peroxidase reaction in wells containing known amounts of eosinophils or neutrophils.

Immunofluorescence flow cytometry. Immunofluorescence flow cytometry was performed as previously described (25). Eosinophil and neutrophil preparations used in these assays were $>98 \%$ pure. Peripheral blood mononuclear cells were obtained by Ficoll-Hypaque separation. The cell populations comprised an average of $70 \%$ lymphocytes and $30 \%$ monocytes $(29)$. Leukocytes $\left(5 \times 10^{5}\right)$ were suspended in $50 \mu \mathrm{l}$ PBS- $0.1 \%$ BSA containing MAb P4C2 or MAb HP 2/1 (1:50 dilution of hybridoma supernatant media), MAb 60.3 or MAb 4B9 $(20 \mu \mathrm{g} / \mathrm{ml})$. The cells were incubated for $20 \mathrm{~min}$ at $4^{\circ} \mathrm{C}$, washed free of unbound antibody, and incubated again at $4^{\circ} \mathrm{C}$ for $20 \mathrm{~min}$ with a 1:50 dilution of FITC goat anti-mouse IgG (Sigma). After washing, the cells were suspended in $500 \mu \mathrm{l}$ of $1 \%$ paraformaldehyde in PBS and stored at $4^{\circ} \mathrm{C}$. The mean fluorescence of each cell population was quantified by a flow cytometer (EPICS-C; Coulter Corp.; Hialeah, FL) with quantitative determination of peak fluorescence intensity.

Monoclonal antibodies. MAb 60.3 is of the IgG2a subclass and recognizes the CD18 subunit (common beta-chain) of the CD11/CD18 antigen complex (32). MAb 4B9 is a murine IgG1 and recognizes cells transfected with VCAM-1 but not cells that are transfected with intercellular adhesion molecule-1 (ICAM-1) or endothelial leukocyte adhesion molecule-1 (ELAM-1) cDNA (23). MAb BB11 is a murine IgG2b that recognizes a functional epitope on ELAM-1 (33), and was a gift of Drs. Christopher Benjamin and Roy Lobb, Biogen Inc., Cambridge, MA. MAb P4C2 is a murine IgG3 that recognizes an epitope on CD49d and (34) and was a gift of Dr. Elizabeth Wayner, Cytel Corp., La Jolla, CA (34). Monoclonal antibody HP2/1 is a murine IgG1 antibody that binds to an epitope on CD49d and was a gift of Dr. F. Sanchez-Madrid (35). MAb P4C10 is a murine IgG 1 that recognizes a functional epitope on CD29 (34), and was a gift of Dr. Elizabeth Wayner.

Reagents. Escherichia coli 055:B5 LPS, extracted by phenol/water, was obtained from Sigma Chemical Company. The LPS preparation was suspended in PBS at a concentration of $1.5 \mathrm{mg} / \mathrm{ml}$, dispersed by sonication for $5 \mathrm{~min}$ at $4^{\circ} \mathrm{C}$, and stored in aliquots at $-35^{\circ} \mathrm{C}$ until used. Phorbol-12-myristate-13 acetate (PMA; Sigma) was dissolved at $1 \mathrm{mg}$ / $\mathrm{ml}$ in DMSO (Eastman Kodak Co., Rochester, NY) and stored as stock 
solution at $-35^{\circ} \mathrm{C}$. Purified recombinant human IL-1 alpha $(1,000$ $\mathrm{U} / \mathrm{ml}$ ) (IL-1) was purchased from Boehringer Mannheim $\mathrm{GmbH}$, Mannheim, FRG. Human recombinant TNF-alpha was a generous gift of Prof. R. Lax, Bissendorf Biochemicals GmbH, Hannover, FRG.

Statistics. Significance was determined by paired, two-tailed $t$ test.

\section{Results}

Influence of anti-CD18, anti-VCAM-1, and anti-ELAM-1 MAb on eosinophil adherence to $H E C$. Adherence assays were performed in the presence or absence of blocking MAbs to the induced endothelial ligands ELAM-1, VCAM-1, or the leukocyte receptors CD1 1/CD18 and VLA-4. As reported previously (15), eosinophils adhered spontaneously to untreated HEC (Table I $a$ ). Basal adherence of eosinophils to HEC was not significantly affected by the anti-VCAM-1 MAb 4B9, the antiELAM-1 MAb BB11, or the CD18 MAb 60.3. Pretreatment of HEC with LPS caused a significant increase in eosinophil adherence above control values, which was significantly reduced by MAb 4B9 or MAb 60.3. Moreover, adherence to LPS-stimulated HEC was reduced to that of unstimulated HEC when MAb 60.3 was used in combination with MAb 4B9. In con-

Table I. Effect of anti-VCAM-1, anti-CD18, and anti-ELAM-1 $M A b$ on Eosinophil and Neutrophil Adherence to HEC

\begin{tabular}{lccc}
\hline & \multicolumn{3}{c}{ Percent adherence } \\
\cline { 2 - 4 } & \multicolumn{3}{c}{$\begin{array}{c}\text { PMA-stimulated } \\
\text { eosinophils }\end{array}$} \\
\hline & & & \\
(a) Eosinimulated & LPS-treated HEC & \\
Control & & & \\
MAb 4B9 & $17.0 \pm 2.2$ & $29.4 \pm 2.0$ & $58.7 \pm 3.8$ \\
MAb 60.3 & $15.6 \pm 2.6$ & $17.1 \pm 2.3^{*}$ & $53.7 \pm 2.3$ \\
MAb 4B9 + MAb 60.3 & $13.6 \pm 1.6$ & $19.7 \pm 0.4^{*}$ & $20.8 \pm 5.2^{*}$ \\
MAb BB11 & $13.8 \pm 2.3$ & $11.0 \pm 1.5^{* \ddagger}$ & $20.3 \pm 4.8^{*}$ \\
MAb BB11 + MAb 60.3 & $14.7 \pm 3.2$ & $33.1 \pm 4.4$ & $64.8 \pm 3.1$ \\
(b) Neutrophils (4) & & $24.3 \pm 1.4$ & $25.5 \pm 3.0^{*}$ \\
Control & $6.6 \pm 0.4$ & $24.0 \pm 4.7$ & $49.1 \pm 6.3$ \\
MAb 4B9 & $5.8 \pm 0.4$ & $24.0 \pm 5.1$ & $45.0 \pm 8.0$ \\
MAb 60.3 & $4.0 \pm 0.3$ & $14.1 \pm 1.8^{*}$ & $3.5 \pm 0.8^{*}$ \\
MAb 4B9 + MAb 60.3 & ND & $14.3 \pm 1.0^{*}$ & ND \\
MAb BB11 & $4.5 \pm 0.2$ & $13.2 \pm 3.4^{*}$ & $48.5 \pm 3.5$ \\
MAb BB11 + MAb 60.3 & ND & $3.3 \pm 0.8^{\ddagger}$ & ND \\
\hline
\end{tabular}

HEC monolayers were pretreated for $4 \mathrm{~h}$ with control medium or medium containing $E$. coli $\mathrm{LPS}(100 \mathrm{ng} / \mathrm{ml})$. Before the assay, eosinophils or neutrophils suspended in PBS containing $5 \mathrm{mM}$ glucose, 1 $\mathrm{mM} \mathrm{CaCl}$, and $1 \mathrm{mM} \mathrm{MgCl}$ were incubated for $15 \mathrm{~min}$ at room temperature in the presence or absence of MAb $60.3(20 \mu \mathrm{g} / \mathrm{ml})$ and HEC monolayers were incubated in the presence or absence of the antiVCAM-1 MAb 4B9 $(20 \mu \mathrm{g} / \mathrm{ml})$ or the anti-ELAM-1 MAb BB1 $1(20$ $\mu \mathrm{g} / \mathrm{ml}$ ). Leukocytes were then added to HEC monolayers followed by PBS (medium) or PMA ( $100 \mathrm{ng} / \mathrm{ml}$, final). Percentage leukocyte adherence was determined after a $30-\mathrm{min}$ incubation at $37^{\circ} \mathrm{C}$. Values represent the means $+\mathrm{SE}$ of $(n)$ experiments with four replicate wells in each experiment. ND, not done. ${ }^{*} P<0.005$ (paired $t$ test) compared to adherence in the absence of MAb (controls). The other results were not significantly different from control values. ${ }^{\ddagger} P<0.005$ for adherence of MAb 60.3- and MAb 4B9-treated eosinophils vs. MAb 60.3-treated eosinophils to LPS-pretreated HEC and for adherence of MAb 60.3- and MAb BB11-treated neutrophils vs. MAb 60.3-treated neutrophils to LPS-pretreated HEC. trast, MAb BB11 had no effect on eosinophil adherence to unstimulated or LPS-stimulated HEC. Similar results were obtained when HEC were pretreated with IL-1 $(10 \mathrm{U} / \mathrm{ml})$ or with TNF (500 U/ml). Treatment of HEC with IL-1 increased eosinophil adherence from basal values of $18.5 \% \pm 2.5$ to $37.5 \% \pm 2.8$. MAb 4B9 and MAb 60.3 reduced IL-1-stimulated adherence to $27.5 \% \pm 1.8$ and $25 \% \pm 2.0$, respectively, and to $15.5 \% \pm 1.5$ when the two MAbs were used in combination. Eosinophil adherence to TNF-treated HEC was $41.0 \% \pm 3.8$, but it was reduced to $31.0 \% \pm 2.6$ and $31.1 \% \pm 2.8$ by MAb 4B9 and MAb 60.3 , respectively, and to $13.0 \% \pm 0.9$ by the combination of MAb 4B9 and MAb 60.3. In contrast, no inhibition of eosinophil adherence to IL-1- or TNF-treated HEC was obtained with MAb BB11 (means \pm SD of four replicate wells in one experiment). Inhibition caused by MAb 4B9 was due to an effect on the endothelial cell rather than on the eosinophil, since preincubation of eosinophils with MAb 4B9 followed by washing did not inhibit subsequent eosinophil adherence to LPS-pretreated HEC (not shown). Finally, as shown in Table I $a$, PMA-stimulated adherence of eosinophils was completely inhibited by MAb 60.3 but was not significantly inhibited by MAb 4B9 or by MAb BB11.

The behavior so far described for eosinophils differed in several respects from that of neutrophils. Unstimulated adherence of neutrophils (Table I $b$ ) was low $(6.6 \% \pm 0.4)$ as compared to unstimulated adherence of eosinophils $(17.6 \% \pm 2.6)$. As reported previously $(18,19)$, neutrophil adherence was significantly increased by stimulation with PMA or by pretreatment of HEC with LPS. No influence of MAb 4B9 was observed on neutrophil adherence to LPS-treated HEC. In contrast, neutrophil adherence to LPS-treated HEC was inhibited by $45 \%$ by MAb BB 11 and by $42 \%$ by MAb 60.3 , respectively, and was inhibited by $87 \%$ when the two MAb were used in combination. PMA-stimulated adherence of neutrophils was completely inhibited by MAb 60.3 , but was not influenced by MAb 4B9 or MAb BB11.

Influence of anti-VLA-4 MAb on eosinophil adherence to $H E C$. Previous studies have shown that antibodies to the VLA4 integrin receptor block lymphocyte adherence to VCAM-1 on activated endothelium (34). Since eosinophil adherence in our assays was inhibited by anti-VCAM-1 MAb 4B9, the possibility arose that the VLA-4 molecule was also involved in eosinophil adherence to activated HEC. Hence, a search for VLA-4 on eosinophils was carried out. Table II compares the binding of two VLA-4 alpha-chain-specific MAbs (CD49d) to

Table II. Expression of Adhesion Proteins on Peripheral Blood Leukocytes

\begin{tabular}{lrrr}
\hline & Eosinophils & Neutrophils & Mononuclear cells \\
\hline MAb & & & \\
P4C2 (CD49d) & $26.7 \pm 1.4(3)$ & $0(2)$ & $15.3 \pm 2.2(3)$ \\
HP2/1 (CD49d) & $25.3 \pm 1.8(3)$ & $0(2)$ & $15.3 \pm 3.3(3)$ \\
60.3 (CD18) & $122.3 \pm 2.7(3)$ & $155(2)$ & $100.7 \pm 3.2(3)$ \\
4B9 (VCAM-1) & $0(3)$ & $0(2)$ & $0(3)$
\end{tabular}

Binding of MAbs was assayed by flow cytometry as described in Methods. Values for net mean peak fluorescence were calculated by subtracting values obtained with FITC-conjugated second antibody alone and represent the mean $\pm \mathrm{SE}$ of $(n)$ experiments. 
eosinophils, neutrophils, or PBMCs. The CD49d MAbs P4C2 and HP2/1 bound to eosinophils as well as to mononuclear cells, but not to neutrophils. As expected, all cell types bound the anti-CD18 MAb 60.3 but none bound the anti-VCAM-1 MAb 4B9. Thereafter, studies on the effect of anti-VLA-4 antibodies on eosinophil adherence were carried out. As shown in Table III, the CD49d MAb P4C2 significantly inhibited eosinophil adherence to LPS-pretreated HEC, but not to untreated HEC. The anti-VCAM-1 MAb 4B9 also inhibited eosinophil adherence to LPS-treated HEC. However, no additive effect was obtained when MAb P4C2 and MAb 4B9 were used in combination, thus suggesting that the two antibodies exerted their effect on the same adherence mechanism. An inhibitory effect on eosinophil adherence was also obtained by using the CD49d MAb HP 2/1 and the CD29 MAb P4C10. Monoclonal antibody HP2/1 inhibited eosinophil adherence to LPS-treated HEC by $68.2 \%$ in one experiment and MAb P4C10 by $45.9 \%$ and $34.8 \%$ in two experiments (results not shown). Finally, it is important to note that adherence of PMA-stimulated eosinophils to untreated HEC was not inhibited at all by the CD49d MAb P4C2 (Table III).

Influence of temperature on eosinophil adherence to HEC. Adherence assays were performed at $37^{\circ} \mathrm{C}$ or at $4^{\circ} \mathrm{C}$ (Fig. 1). Eosinophil adherence to HEC was stimulated either by PMA or by preincubating HEC monolayers with LPS. Values of eosinophil adherence at $37^{\circ} \mathrm{C}$ were $16.5 \% \pm 1.3,30.8 \% \pm 2.5$, and $64.6 \% \pm 4.2$ for unstimulated and for LPS- and PMA-stimulated adherence, respectively. However, both unstimulated and stimulated adherence of eosinophils was almost abolished at $4^{\circ} \mathrm{C}$. Again neutrophils behaved quite differently from eosinophils. Their adherence to unstimulated HEC was low at $37^{\circ} \mathrm{C}$ and at $4^{\circ} \mathrm{C}$. PMA markedly increased neutrophil adherence to unstimulated $\mathrm{HEC}$ at $37^{\circ} \mathrm{C}$, but not at $4^{\circ} \mathrm{C}$. As described

Table III. Effect of anti-VLA-4 and anti-VCAM-1 MAbs on Eosinophil Adherence to HEC

\begin{tabular}{lccc}
\hline & \multicolumn{3}{c}{ Percent adherence } \\
\cline { 2 - 4 } & Unstimulated & $\begin{array}{c}\text { LPS-stimulated } \\
\text { HEC }\end{array}$ & $\begin{array}{c}\text { PMA- } \\
\text { stimulated } \\
\text { eosinophils }\end{array}$ \\
\hline MAb & & & \\
$\quad$ control & $18.6 \pm 1.2$ & $29.6 \pm 1.4$ & $63.3 \pm 6.7$ \\
$\begin{array}{l}\text { MAb P4C2 (CD49d) } \\
\text { MAb 4B9 }\end{array}$ & $18.8 \pm 1.6$ & $15.7 \pm 2.3^{*}$ & $63.5 \pm 6.3$ \\
$\quad$ (anti-VCAM-1) & $16.6 \pm 2.0$ & $19.1 \pm 1.8^{\ddagger}$ & ND \\
MAb P4C2 + MAb 4B9 & $17.8 \pm 2.0$ & $19.5 \pm 2.4^{\ddagger}$ & ND \\
\hline
\end{tabular}

HEC monolayers were pretreated for $4 \mathrm{~h}$ with control medium or medium containing $E$. coli $\mathrm{LPS}(100 \mathrm{ng} / \mathrm{ml})$. Before the assay, eosinophils suspended in PBS containing $5 \mathrm{mM}$ glucose, $1 \mathrm{mM} \mathrm{CaCl}_{2}$, and $1 \mathrm{mM} \mathrm{MgCl}_{2}$, were incubated for $15 \mathrm{~min}$ at room temperature in the presence or absence of MAb P4C2 (1:50 dilution of hybridoma supernatant medium) and HEC monolayers were incubated in the presence or absence of MAb 4B9 $(10 \mu \mathrm{g} / \mathrm{ml})$ : leukocytes were then added to HEC monolayers followed by PBS (medium) or PMA (100 $\mathrm{ng} / \mathrm{ml}$, final). Percentage leukocyte adherence was determined after a 30 -min incubation at $37^{\circ} \mathrm{C}$. Values represent the means $\pm \mathrm{SE}$ of six experiments with three replicate wells in each experiment. ND, not done. ${ }^{*} P<0.005 ;{ }^{\ddagger} P<0.025$ (paired $t$ test) compared to adherence in the absence of MAb (controls). The other results were not significantly different from control values.

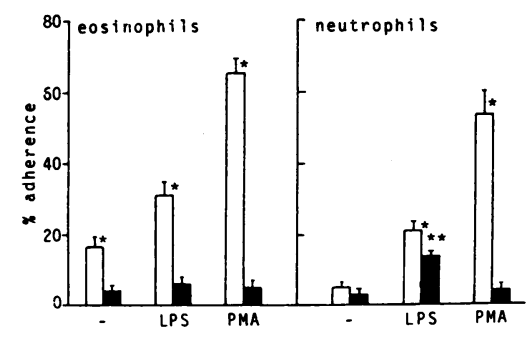

Figure 1. Effect of temperature on eosinophil and neutrophil adherence to HEC. HEC monolayers were pretreated at $37^{\circ} \mathrm{C}$ for $4 \mathrm{~h}$ with medium alone (control) or with medium containing $E$. coli LPS $(100 \mathrm{ng} / \mathrm{ml})$. Eosinophils or neutrophils suspended in PBS containing $5 \mathrm{mM}$ glucose, $1 \mathrm{mM} \mathrm{CaCl}_{2}$, and 1 $\mathrm{mM} \mathrm{MgCl}$ were added to HEC monolayers with medium (control) or with PMA $(100 \mathrm{ng} / \mathrm{ml})$. For the adherence assay at $4^{\circ} \mathrm{C}$, leukocytes were incubated on ice and HEC were incubated in a cold room (2$4^{\circ} \mathrm{C}$ ) for $30 \mathrm{~min}$ before the assay. Percentage leukocyte adherence was determined after a $30-\mathrm{min}$ incubation at $37^{\circ} \mathrm{C}$ or at $4^{\circ} \mathrm{C}$. Values are means $\pm \mathrm{SE}$ of six experiments, with four replicate wells in each experiment. ${ }^{*} P<0.001$ for leukocyte adherence at $37^{\circ} \mathrm{C}$ vs. adherence at $4^{\circ} \mathrm{C} .{ }^{* *} P<0.002$ for neutrophil adherence to LPS-pretreated HEC vs. untreated $\mathrm{HEC}$ at $4^{\circ} \mathrm{C}$. $\square, 37^{\circ} \mathrm{C} ; \square, 4^{\circ} \mathrm{C}$

previously (19), stimulation of HEC by LPS pretreatment resulted in an increased adherence both at $37^{\circ} \mathrm{C}$ and at $4^{\circ} \mathrm{C}$. Neutrophil adherence to LPS-treated HEC at $4^{\circ} \mathrm{C}$ was completely inhibited by MAb BB1 1 (not shown), suggesting involvement of ELAM-1 in this adherence.

Divalent cation requirements for eosinophil adherence to $H E C$. The experiments whose results are shown in Table I and Fig. 1 were performed in PBS medium containing both $\mathrm{Ca}^{++}(1$ $\mathrm{mM})$ and $\mathrm{Mg}^{++}(1 \mathrm{mM})$. Divalent cation requirements for the various mechanisms of adherence were further investigated in greater detail at $37^{\circ} \mathrm{C}$ (Fig. 2). Detachment of HEC occurred in the absence of both calcium and magnesium, or in the presence of EDTA ( $1 \mathrm{mM})$, thereby preventing us from determining eosinophil adherence to HEC under these conditions. When the assay was performed in the presence of $\mathrm{Ca}^{++}$only $(1 \mathrm{mM}), \mathrm{a}$

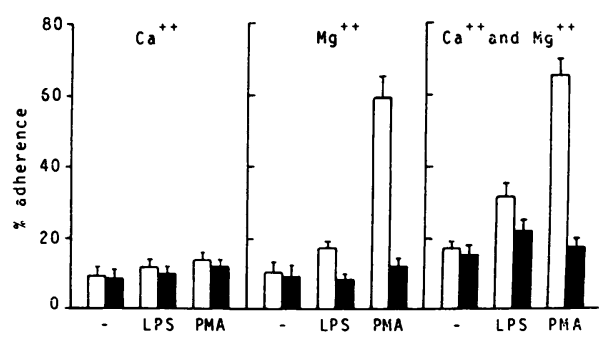

Figure 2. Effect of $\mathrm{Ca}^{++}$and $\mathrm{Mg}^{++}$on eosinophil adherence to HEC. HEC monolayers were pretreated at $37^{\circ} \mathrm{C}$ for $4 \mathrm{~h}$ with medium alone or medium containing E. coli LPS $(100 \mathrm{ng} / \mathrm{ml})$. Eosinophils were suspended in PBS containing $5 \mathrm{mM}$ glucose with $1 \mathrm{mM} \mathrm{CaCl}{ }_{2}$ only, or with $1 \mathrm{mM} \mathrm{MgCl}{ }_{2}$ only, or with both cations. Eosinophils were then added to HEC monolayers followed by PBS (control) or PMA $(100 \mathrm{ng} / \mathrm{ml})$. Percentage eosinophil adherence was determined after a 30 -min incubation at $37^{\circ} \mathrm{C}$. Values are means $\pm \mathrm{SE}$ of five experiments with four replicate wells in each experiment. Statistical significance (by paired $t$ test): $P<0.05$ for adherence of MAb 60.3-treated eosinophils vs. untreated eosinophils to LPS-treated HEC in the presence of $\mathrm{CaCl}_{2}$ and $\mathrm{MgCl}_{2} . P<0.02$ for unstimulated adherence in the presence of $\mathrm{CaCl}_{2}$ only or $\mathrm{MgCl}_{2}$ only vs. adherence in the presence of both cations, and for adherence of MAb 60.3-treated eosinophils to LPS-treated HEC vs. untreated HEC in the presence of $\mathrm{CaCl}_{2}$ and $\mathrm{MgCl}_{2}$., , medium; $\square$, MAb 60.3. 
definite proportion $(8.9 \% \pm 1.9)$ of eosinophils adhered to untreated HEC. Of note, unstimulated eosinophil adherence at $37^{\circ} \mathrm{C}$ in the presence of $\mathrm{Ca}^{++}$only (as well as in the presence of $\mathrm{Mg}^{++}$only) was still statistically greater than adherence at $4^{\circ} \mathrm{C}$ in the presence of $\mathrm{Ca}^{++}$only, or $\mathrm{Mg}^{++}$only, or both cations $(P$ $<0.05$, four experiments). At $37^{\circ} \mathrm{C}$ and in the presence of $\mathrm{Ca}^{++}$ only, however, there was no increase of eosinophil adherence above control levels with LPS-pretreated HEC or in the presence of PMA. Moreover, adherence in the presence of $\mathrm{Ca}^{++}$ only was unaffected by MAb 60.3.

In the presence of $\mathrm{Mg}^{++}$only $(1 \mathrm{mM})$, unstimulated eosinophil adherence was similar to that observed in the presence of $\mathrm{Ca}^{++}$only. Eosinophil adherence to LPS-pretreated HEC, however, was significantly increased as compared to adherence to untreated HEC and was completely inhibited by MAb 60.3. Furthermore, in the presence of $\mathrm{Mg}^{++}$only, PMA stimulated eosinophil adherence and this was again inhibited by MAb 60.3. These results indicate that, in the presence of $\mathrm{Mg}^{++}$only, eosinophil adherence due to LPS pretreatment of HEC or to PMA is accounted for, almost completely, by CD11/CD18. Raising $\mathrm{Mg}^{++}$concentration to $2 \mathrm{mM}$ did not lead to appreciable changes in the results obtained with $1 \mathrm{mM} \mathrm{Mg}^{++}$(not shown).

In the presence of both $\mathrm{Ca}^{++}$and $\mathrm{Mg}^{++}$, unstimulated eosinophil adherence was statistically greater than in the presence of $\mathrm{Ca}^{++}$only or $\mathrm{Mg}^{++}$only (Fig. 2). Adherence to LPS-treated HEC was further increased above levels of unstimulated adherence in the presence of $\mathrm{Ca}^{++}$and $\mathrm{Mg}^{++}$, or levels of adherence to LPS-treated HEC in the presence of $\mathrm{Mg}^{++}$only, and was only partially inhibited by MAb 60.3 (see also Table I). In contrast, PMA-stimulated adherence of eosinophils in the presence of $\mathrm{Ca}^{++}$and $\mathrm{Mg}^{++}$was similar to that observed with $\mathrm{Mg}^{++}$ only, and was completely inhibited by the CD18 mAb 60.3.

Influence of PMA on CD11/CD18-dependent and-independent adherence mechanisms. In a previous study, we found that neutrophil CD11/CD18-independent adherence is downregulated when neutrophils are activated with PMA (25). To define the effect of phorbol ester on CD11/CD18-independent adherence of eosinophils, eosinophil adherence to HEC or LPStreated HEC was stimulated with PMA in the presence of the CD18 (MAb) 60.3. As shown in Fig. 3, eosinophil adherence to

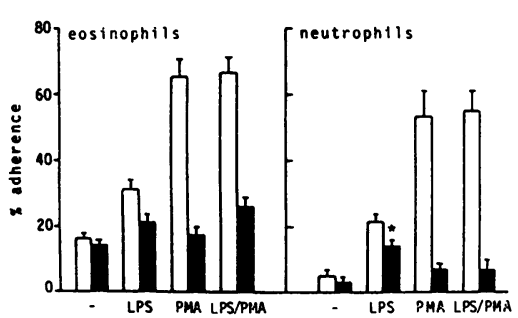

Figure 3. Effect of PMA on eosinophil and neutrophil adherence to LPS-treated HEC in the presence of CD18 MAb. HEC monolayers were pretreated for $4 \mathrm{~h}$ with medium alone or medium containing $E$. coli LPS $(100 \mathrm{ng} / \mathrm{ml})$. Eosinophils or neutrophils suspended in PBS containing $5 \mathrm{mM}$ glucose, $1 \mathrm{mM} \mathrm{CaCl}_{2}$, and $1 \mathrm{mM} \mathrm{MgCl}_{2}$ were incubated for $15 \mathrm{~min}$ at room temperature in the presence or absence of the CD18 MAb 60.3 (20 $\mu \mathrm{g} / \mathrm{ml})$. Leukocytes were then added to HEC monolayers followed by PBS (control) or PMA $(100 \mathrm{ng} / \mathrm{ml})$. Percentage leukocyte adherence was determined after a 30 -min incubation at $37^{\circ} \mathrm{C}$. Values are means \pm SE of six experiments with four replicate wells in each experiment. ${ }^{*} P<0.01$ (paired $t$ test) compared to adherence of unstimulated neutrophils to LPS-pretreated HEC in the presence of MAb 60.3 alone or PMA alone. $\square$, medium; $\bullet$, MAb 60.3. untreated HEC was potently stimulated by PMA in the absence of MAb 60.3, but it remained unaffected in its presence. Similarly, adherence of eosinophils to LPS-treated HEC was increased by PMA in the absence of MAb 60.3 , but no change (i.e., no up- or downregulation) of adherence between PMAtreated and untreated eosinophils was observed when MAb 60.3 was present in the assay. Control experiments were performed with neutrophils. These cells adhered minimally to untreated HEC, but bound avidly to HEC when stimulated with PMA. Pretreatment of HEC with LPS also markedly increased neutrophil adherence. Adherence of neutrophils to LPStreated HEC was only partially (by $50 \%$ ) inhibited by MAb 60.3, whereas PMA-stimulated neutrophil adherence to untreated HEC was completely inhibited by this MAb. However, MAb 60.3 completely abolished neutrophil adherence to LPStreated HEC when PMA was added with the neutrophils, thus indicating that stimulation with PMA downregulated the CD11/CD18-independent mechanism of neutrophil adherence.

\section{Discussion}

Our results indicate that at least three binding mechanisms are involved in eosinophil adherence to endothelial cells: (a) a mechanism(s) that accounts for a small but definite (15-17\%) proportion of eosinophil adherence to unstimulated HEC (basal adherence); (b) a mechanism involving the leukocyte adhesion complex CD11/CD18. This mechanism of adherence accounts, almost completely, for the increase of adherence following eosinophil activation by agents such as PMA (eosinophil-dependent adherence), and in part for the adherence of unstimulated eosinophils to endothelial cells that have been pretreated with LPS, TNF, or IL-1 (endothelial-dependent adherence); and (c) a mechanism specific for endothelial-dependent adherence that involves the interaction of the VLA- 4 integrin receptor $(20,36)$ on eosinophils with the cytokine- or LPSinducible endothelial adhesion molecule VCAM-1 (21) (also known as INCAM-1 10, 22).

Kimani et al. (15) have previously reported values from $25 \%$ to $35 \%$ for basal eosinophil adherence to endothelial cells, whereas Lamas et al. (14) have reported much lower values $(<5 \%)$. The higher values of basal eosinophil adherence obtained by us, in comparison to Lamas et al., were not accounted for by a failure to remove the nonadherent cells, as indicated by parallel adhesion assays with eosinophils and neutrophils, using the same technique, and, in particular, the same washing procedure, in which the unstimulated adherence of eosinophils was significantly higher than that of neutrophils, i.e., $15-17 \%$ vs. $5-6 \%$. The basal adherence of eosinophils was temperature-dependent, since it occurred at $37^{\circ} \mathrm{C}$ but not at $4^{\circ} \mathrm{C}$, suggesting that an active binding mechanism(s) is involved. In addition, basal eosinophil adherence required $\mathrm{Ca}^{++}$ or $\mathrm{Mg}^{++}$and was greater in the presence of both cations. These results suggest that two distinct adherence mechanisms may be involved in unstimulated adherence of eosinophils, one requiring both $\mathrm{Ca}^{++}$and $\mathrm{Mg}^{++}$, and the other requiring either $\mathrm{Ca}^{++}$or $\mathrm{Mg}^{++}$. Further studies may identify the molecule(s) involved in this basal adherence. The higher spontaneous adherence of eosinophils, as compared to neutrophils, may account for the propensity of blood eosinophils to emigrate in the extravascular space in physiologic conditions, i.e., in the absence of inflammatory stimuli (1-4). 
In a recent study, Lamas et al. (14) reported that eosinophil adherence was increased by soluble agents such as the tumor promoter PMA, the chemotactic bacterial peptide FMLP, and the chemotactic factor for eosinophils PAF, as well as by pretreatment of HEC with LPS, TNF, or IL-1. The proadhesive effect of PMA, FMLP, or PAF was exerted through eosinophil activation, since the agents stimulated eosinophil adherence on gelatin coated dishes as well as on HEC. Similar results were obtained by Kimani et al. (15) by stimulating eosinophil adherence with PAF. PMA-, FMLP-, and PAF-stimulated adherence involved the activation of the glycoprotein adhesion complex CD1 la,b,c/CD18 (LFA-1, Mac-1, p150/95), since adherence was completely inhibited by MAb directed against the common CD18 subunit $(14,15)$ of CD1 1/CD18. In contrast, eosinophil adherence induced by LPS, TNF, or IL-1 pretreatment of HEC, was only in part inhibited by the anti-CD18 MAb, suggesting that a CD11/CD18-independent mechanism was also involved in endothelial-mediated adherence (14). Similarly, we found that the CD18 MAb 60.3 completely inhibited PMA-induced adherence of eosinophils to untreated HEC, but only partially inhibited eosinophil adherence to LPS-, TNF-, or IL1 -treated HEC. Three adhesion molecules have been identified that can be upregulated by endothelial cells upon stimulation with cytokines or LPS: $(a)$ ICAM-1, which functions as ligand for the leukocyte adhesion receptor $\mathrm{CD} 11 \mathrm{a} / \mathrm{CD} 18(37,38)$; $(b)$ ELAM-1 (39), which is involved in the adherence to endothelium of neutrophils and monocytes (39a); and (c) VCAM-1, recently identified as an endothelial surface molecule involved in adherence of peripheral blood lymphocytes $(22,23)$ and monocytes (22) (39a), and some lymphocytic cell lines $(21,34)$. In our adhesion assays, the anti-VCAM-1 MAb 4B9 caused a significant inhibition of eosinophil adherence to LPS- or cytokine-treated HEC.' Moreover, when MAb 4B9 was used in combination with the CD18 MAb 60.3, the increase of adherence caused by the LPS or TNF or IL-1 treatment of HEC was reduced to control values (i.e., values of unstimulated adherence). This indicates that VCAM- 1 and the endothelial ligand for CD1 1/CD18, most likely ICAM-1 $(37,38)$, are the endothelial adherence molecules specifically involved in eosinophil binding to LPS- or cytokine-stimulated HEC. Recently, Elices et al. (36) reported that specific adherence of VLA-4-transfected cells to VCAM-1 expressed on either HEC monolayers, or on COS cells transfected with VCAM-1, was completely inhibited by anti-VLA-4 MAb. Using CD11/CD18-deficient lymphocytes, Schwartz et al. (34) demonstrated that lymphocyte binding to TNF-stimulated HEC was inhibited by MAbs to VLA-4 (CD49d/CD29) or VCAM-1. Similarly, we found that two anti-VLA-4 MAbs inhibited eosinophil adherence to LPS-treated HEC, with no additive effect when anti-VLA-4 and anti-VCAM-1 MAb were used in combination. Hence, the eosinophil receptor recognizing VCAM-1 appears to be the integrin receptor VLA-4. In contrast to the anti-VCAM-1 MAb, the anti-ELAM-1 MAb BB11, that completely inhibited CD11/CD18-independent neutrophil adherence to LPStreated HEC, did not affect eosinophil adherence to LPS-, TNF- or IL-1-treated HEC, thus excluding involvement of ELAM-1 in endothelial-dependent eosinophil adherence. Involvement of ELAM-1 in eosinophil adherence to stimulated HEC could be excluded in our experiments also on the basis of the following observations: (a) eosinophil adherence to LPStreated HEC was completely inhibited at $4^{\circ} \mathrm{C}$, whereas neutrophil adherence was partially maintained. The mechanism of neutrophil adherence at $4^{\circ} \mathrm{C}$ involves ELAM-1, since the CD11/CD18-dependent adherence mechanism was inactive at $4^{\circ} \mathrm{C}$, and since neutrophil adherence at $4^{\circ} \mathrm{C}$ was abolished by the anti-ELAM-1 MAb BB11. (b) Neutrophil CD11/CD18-independent adherence to LPS-treated HEC was reported to be active in the presence of $\mathrm{Ca}^{++}$only (19). In contrast, CD11/ CD18-independent adherence of eosinophils to LPS-treated HEC (i.e., adherence in the presence of anti-CD18 MAb) required both $\mathrm{Ca}^{++}$and $\mathrm{Mg}^{++}$. (c) As described previously (25), CD11/CD18-independent adherence of neutrophils to LPStreated HEC was downregulated in the presence of PMA, an effect of PMA that may be related with the reported downregulation of neutrophil MEL-14 antigen (40). In contrast, CD11/ CD18-independent adherence of eosinophils to LPS-treated HEC was unaffected by PMA, thus indicating that VLA-4/ VCAM-1-dependent eosinophil adherence is not downregulated upon eosinophil activation. The last result may provide a possible explanation for the observed eosinophilic infiltration in tissues of patients with partial or complete deficiency of the leukocyte membrane CD11/CD18 adhesion complex (leukocyte adhesion deficiency, LAD) (41). LAD neutrophils adhere in vitro to LPS- or cytokine-stimulated HEC by the CD11/ CD18-independent mechanism $(18,19)$. However, neutrophils fail to accumulate in infected tissues in LAD patients (41). Since the CD1 1/CD18-independent adherence mechanism of LAD neutrophils is inhibited in vitro when the neutrophils are activated by agents such as PMA or FMLP, and in this condition they do not adhere to stimulated HEC (25), a possible explanation for the behavior of neutrophils in LAD patients is that, in vivo, the CD11/CD18-independent adherence mechanism is downregulated by inflammatory stimuli produced at sites of inflammation $(25,40)$. The absence of downregulation of eosinophil CD11/CD18-independent adherence mechanism may then account for eosinophil adherence to and migration across the endothelium in LAD patients, given that LAD eosinophils are endowed with the same CD11/CD18-independent mechanisms of adherence as normal eosinophils.

\section{Acknowledgments}

We thank R. Gagliardi, F. Bassan, A. Parenzan, and A. Knowles for technical assistance.

This work was supported in part by grants from the U. S. Public Health Service (HL 18645), the MPI and the CNR of Italy, Target Project on Biotechnology and Bioinstrumentation, and grant No. 89.02733.04. Dr. Menegazzi is a recipient of a Research Doctor Fellowship from the Anna Villa Rusconi Foundation. Dr. Carlos is a recipient of a Clinician-Scientist Award from the American Heart Association. Dr. Harlan is an Established Investigator of the American Heart Association. Dr. Nardon is a recipient of a grant from the Italian Association for Cancer Research (AIRC).

\section{References}

1. Hudson, G. 1968. Quantitative study of the eosinophil granulocytes. Semin. Hematol. 5:166-186.

2. Stryckmans, P. A., E. P. Cronkite, M. L. Greenberg, and L. M. Schiffer. 1968. Kinetics of eosinophil leukocyte proliferation in man. In Plenary Session Papers of the Twelfth Congress of the International Society of Haematology. E. R. Jaffe, editor. The International Society of Haematology, New York. p. F19. (Abstr.)

3. Rytomaa, T. 1960. Organ distribution and histochemical properties of eosinophil granulocytes in the rat. Acta Pathol. Microbiol. Scand. 50 (Suppl. 140): 1-118.

4. Ringoen, A. R. 1938. Eosinophil leukocytes and eosinophilia. In Hand- 
book of Haematology. H. Downey, editor. Hamish Hamilton Medical Books, London. 181-208.

5. Nutman, T. B., E. A. Ottesen, and S. G. Cohen. 1989. The eosinophil, eosinophilia, and eosinophil-related disorders. III. Clinical assessments. Allergy Proc. 10:33-46.

6. Nutman, T. B., E. A. Ottesen, and S. G. Cohen. 1989. The eosinophil, eosinophilia, and eosinophil-related disorders. IV. Eosinophil-related disorders (continued). Allergy Proc. 10:47-62.

7. Spry, C. J. F. 1988. Eosinophils in disease. In Eosinophils. A Comprehensive Review, and Guide to the Scientific and Medical Literature. C. J. F. Spry, editor. Oxford University Press, Oxford. 131-316.

8. Migler, R., L. R. De Chatelet, and D. A. Bass. 1978. Human eosinophilic peroxidase: role in bactericidal activity. Blood. 51:445-456.

9. Weiss, S. J., S. T. Test, C. M. Eckmann, D. Ross, and S. Regiani. 1986. Brominating oxidants generated by human eosinophils. Science (Wash. DC). 234:200-203.

10. Jong, E. C., A. F. Mahmond, and S. J. Klebanoff. 1981. Bactericidal activity of eosinophilic peroxidase. J. Immunol. 124:1378-1382.

11. Gleich, G. J., E. Frigas, D. A. Loegering, D. L. Wassom, and D. Steinmuller. 1979. Cytotoxic properties of the eosinophil major basic protein. J. Immunol. 123:2925-2927.

12. Kroegel, C., U. Costabel, and H. Matthys. 1987. Mechanism of membrane damage mediated by eosinophil major basic protein (letter). Lancet. i:1380-1381.

13. Butcher, E. C. 1990. Cellular and molecular mechanisms that direct leukocyte traffic. Am. J. Pathol. 136:3-11.

14. Lamas, A. M., C. M. Mulroney, and R. P. Schleimer. 1988. Studies on the adhesive interaction between purified human eosinophils and cultured vascular endothelial cells. J. Immunol. 140:1500-1505.

15. Kimani, G., M. G. Tonnesen, and P. M. Henson. 1988. Stimulation of eosinophil adherence to human vascular endothelial cells in vitro by platelet-activating factor. J. Immunol. 140:3161-3166.

16. Wardlaw, A. J., R. Moqbel, O. Cromwell, and A. B. Kay. 1986. Plateletactivating factor. A potent chemotactic and chemokinetic factor for human eosinophils. J. Clin. Invest. 78:1701-1706.

17. Sigal, C. E., F. H. Valone, M. J. Holtzman, and E. J. Goetzl. 1987. Preferential human eosinophil chemotactic activity of the platelet-activating factor (PAF) 1-0-hexadecyl-2-acetyl-sn-glyceryl-3-phosphocholine (AGEPC). J. Clin. Immunol. 7:179-184.

18. Pohlman, T. H., K. A. Stanness, P. G. Beatty, H. D. Ochs, and J. M. Harlan. 1986. An endothelial cell surface factor(s) induced in vitro by lipopolysaccharide, interleukin-1, and tumor necrosis factor-alpha increases neutrophil adherence by a CDw-dependent mechanism. J. Immunol. 136:4548-4553.

19. Dobrina, A., B. R. Schwartz, T. M. Carlos, H. D. Ochs, P. G. Beatty, and J. M. Harlan. 1989. CD11/CD18-independent neutrophil adherence to inducible endothelial-leukocyte adhesion molecules (E-LAM) in vitro. Immunology. 67:502-508.

20. Hemler, M. E., C. Huang, Y. Takada, L. Schwarz, J. L. Strominger, and M. L. Clabby, 1987. Characterization of the cell surface heterodimer VLA-4 and related peptides. J. Biol. Chem. 262:11478-11485.

21. Osborn, L., C. Hession, R. Tizard, C. Vassallo, S. Luhowsky, G. ChiRosso, and R. Lobb. 1989. Direct expression cloning of vascular cell adhesion molecule 1, a cytokine-induced endothelial protein that binds to lymphocytes. Cell. 59:1203-1211.

22. Rice, G. E., J. M. Munro, and M. P. Bevilacqua. 1990. Inducible cell adhesion molecule 110 (INCAM-110) is an endothelial receptor for lymphocytes. A CD11/CD18-independent adhesion mechanism. J. Exp. Med. 171:1369-1374.

23. Carlos, T. M., B. R. Schwartz, N. L. Kovach, E. Yee, M. Rosso, L. Osborn, G. Chi-Rosso, R. Lobb, and J. M. Harlan. 1990. Vascular cell adhesion molecule1 mediates lymphocyte adherence to cytokine-activated cultured human endothelial cells. Blood. 76:965-970.

24. Carlos, T. M., and J. M. Harlan. 1990. Membrane proteins involved in phagocyte adherence to endothelium. Immunol. Rev. 114:5-28.
25. Dobrina, A., T. M. Carlos, B. R. Schwartz, P. G. Beatty, H. D. Ochs, and J. M. Harlan. 1990. Phorbol ester causes down-regulation of CD11/CD18-independent neutrophil adherence to endothelium. Immunology. 69:429-434

26. Jaffe, E. A., R. L. Nachman, C. G. Becker, and R. C. Minick. 1973. Culture of human endothelial cells derived from umbilical veins. Identification by morphologic and immunologic criteria. J. Clin. Invest. 52:2745-2756.

27. Thornton, S. C., S. N. Mueller, and E. M. Levine. 1983. Human endothelial cells: use of heparin in cloning and long-term serial cultivation. Science (Wash. DC). 222:623-625.

28. Maciag, T., J. Cerundolo, S. Ilsley, and P. R. and R. Forand. 1979. An endothelial cell growth factor from bovine hypothalamus: identification and partial characterization. Proc. Natl. Acad. Sci. USA. 76:5674-5678.

29. Boyum, A. 1968. Isolation of mononuclear cells and granulocytes from human blood. Scand. J. Clin. Lab. Invest. 21(Suppl. 97):77-81.

30. Andrews, P. C., and N. I. Krinsky. 1981. The reductive cleavage of myeloperoxidase in half, producing enzymically active hemi-myeloperoxidase. J. Biol. Chem. 256:4211-4218.

31. Cramer, R., M. R. Soranzo, P. Dri, R. Menegazzi, A. Pitotti, G. Zabucchi, and P. Patriarca. 1984. A simple reliable assay for myeloperoxidase activity in mixed neutrophil-eosinophil cell suspensions: application to detection of myeloperoxidase deficiency. J. Immunol. Methods. 70:119-125.

32. Beatty, P. G., J. A. Ledbetter, P. G. Martin, T. H. Price, and J. A. Hansen. 1983. Definition of a common leukocyte cell-surface antigen (Gp95-150) associated with diverse cell-mediated immune functions. J. Immunol. 131:29132918.

33. Benjamin, C., I. Douas, G. Chi-Rosso, S. Luhowskyj, M. Rosa, B. Newman, L. Osborn, C. Vassallo, C. Hession, S. Goelz, K. McCarthy, and R. Lobb. 1990. A blocking monoclonal antibody to endothelial-leukocyte adhesion molecule-1 (ELAM1). Biochem. Biophys. Res. Commun. 171:348-353.

34. Schwartz, B. R., E. A. Wayner, T. M. Carlos, H. D. Ochs, and J. M. Harlan. 1990. Identification of surface proteins mediating adherence of CD11/ CD18-deficient lymphoblastoid cells to cultured human endothelium. J. Clin. Invest. 85:2019-2022.

35. Sanchez Madrid, F., M. O. De Londazuri, G. Morago, M. Cebrian, A. Acevedo, and C. Bernabeu. 1986. VLA-3: a novel polypeptide association with the VLA molecular complex: cell distribution and biochemical characterization. Eur. J. Immunol. 16:1343-1349.

36. Elices, M. J., L. Osborn, Y. Takada, C. Crouse, S. Luhowskyj, M. E Hemler, and R. R. Lobb. 1990. VCAM-1 on activated endothelium interacts with the leukocyte integrin VLA-4 at a site distinct from the VLA-4/fibronectin binding site. Cell. 60:577-584.

37. Marlin, S. D., and T. A. Springer. 1987. Purified intercellular adhesion molecule-1 (ICAM-1) is a ligand for lymphocyte function-associated antigen (LFA-1). Cell. 51:813-819.

38. Smith, C. W., R. Rothlein, B. J. Hughes, M. M. Mariscalco, H. E. Rudloff, F. C. Schmalsteig, and D. C. Anderson. 1988. Recognition of an endothelial determinant for CD18-dependent human neutrophil adherence and transendothelial migration. J. Clin. Invest. 82:1746-1756.

39. Bevilacqua, M. P., J. S. Pober, D. L. Mendrick, R. S. Cotran, and M. A. Gimbrone, Jr. 1987. Identification of an inducible endothelial-leukocyte adhesion molecule. Proc. Natl. Acad. Sci. USA. 84:9238-9242.

39a. Carlos, T. M., N. Kovach, B. R. Schwartz, M. Rosa, B. Newman, E. Wayner, C. Benjamin, L. Osborn, R. Lobb, and J. M. Harlan. 1991. Human monocytes bind to two cytokine-induced adhesive ligands on cultured human endothelial cells: ELAM-1 and VCAM-1. Blood. In press.

40. Kishimoto, T. K., M. A. Jutila, E. L. Berg, and E. C. Butcher. Neutrophil Mac-1 and MEL-14 adhesion proteins inversely regulated by chemotactic factors. Science (Wash. DC). 245:1238-1241.

41. Anderson, D. C, F. C. Schmalsteig M. J. Finegold, B. J. Hughes, R. Rothlein, L. J. Miller, S. Kohl, M. F. Tosi, R. L. Jacobs, T. C. Waldrop, et al. 1985. The severe and moderate phenotypes of heritable Mac-1, LFA-1 deficiency: their quantitative deficiency and relation to leukocyte dysfunction and clinical features. J. Infect. Dis. 152:668-689. 